\title{
Influência do Número de Animais por Gaiola sobre o Nível de Ansiedade em Camundongos Rivelilson Mendes de Freitas
}

Farmacêutico, Doutor em Farmacologia, Docente do Curso de Farmácia da Universidade Federal do Piauí, Teresina-PI, Brasil.

Neste número da Revista Neurociências é publicado o estudo sobre a influência do número de animais por gaiola sobre o nível de ansiedade em camundongos ${ }^{1}$. A ansiedade pode ser caracterizada como uma emoção semelhante ao medo, entretanto, no medo há uma ameaça definida. Por outro lado, na ansiedade, a fonte do perigo é incerta ou desconhecida. A ansiedade manifesta-se em diferentes planos (psicológico, fisiológico e comportamental) ${ }^{2}$.

Essa patologia é uma vivência comum de virtualmente qualquer ser humano. A sensação se caracteriza por um sentimento difuso, desagradável, e vago de apreensão, frequentemente, acompanhado por sintomas autonômicos, como cefaleia, perspiração, palpitações, aperto no peito e leve desconforto abdominal. Os sinais e sintomas presentes durante a ansiedade em humanos tende a variar entre as pessoas. No entanto, a referida doença é uma resposta a uma ameaça desconhecida, interna, vaga ou de origem conflituosa. A ansiedade quando considerada simplesmente como um sinal de alerta, pode ser encarada como uma emoção semelhante ao medo, podendo preparar o indivíduo para tomar medidas necessárias, para evitar a ameaça ou, pelo menos, atenuar suas consequências ${ }^{3}$.

O referido estudo desta edição investigou o efeito do número de animais por gaiola sobre o comportamento de ansiedade em camundongos expostos ao labirinto em cruz elevado. Já é sabido que a ansiedade é uma emoção normal, universal do ser humano. Pode ser benéfica em alguns casos, uma vez que conduz uma mobilização e preparo para melhor enfrentar determinadas situaçóes. No entanto, pode se tornar patológica quando muito intensa ou desproporcional ao estímulo que a originou, ou quando surge sem que haja um motivo para isso ${ }^{4}$, sendo, assim, necessário investigar as condiçôes que podem influenciar modelos experimentais sobre o estudo da ansiedade com roedores.
Nesse estudo os autores utilizaram trinta camundongos divididos em duas gaiolas da seguinte forma: em uma gaiola foi colocado um grupo com dez camundongos e na segunda gaiola foi mantido um grupo com vinte animais. Os animais foram observados durante o período de 90 dias de idade, sendo submetidos ao teste do labirinto em cruz elevado. A porcentagem do número de entradas nos braços abertos e a porcentagem de tempo gasto nos braços abertos foram os parâmetros avaliados em ambos os grupos, apenas uma vez no período de cinco minutos. No estudo da psicobiologia da ansiedade, os modelos animais são extremamente úteis, auxiliando na compreensão da sua fisiopatologia e tratamento. Entre os modelos o labirinto em cruz elevado, que inicialmente foi criado para ratos por Pellow et al, e que posteriormente foi adaptado para camundongos por Lister, permite verificar o grau de "ansiedade" do animal ${ }^{5,6}$. Nesse mesmo teste pode ser verificada a diminuição dos parâmetros relacionados à ansiedade após tratamento com drogas ansiolíticas (diazepam, clordiazepóxido), que alivia a ansiedade no homem e parece ter efeito semelhante nos ratos e camundongos neste modelo animal.

No mesmo estudo os autores após os testes comportamentais verificaram que a análise estatística náo detectou diferenças significativas entre os dois grupos na porcentagem do número de entradas e do tempo gasto nos braços abertos. Já foi verificado que a rotina de manipulação de animais de laboratório é essencial para obter resultados satisfatórios. Dessa forma, é importante que durante os estudos comportamentais sejam adotadas práticas para reduzir todo o estresse e ansiedade entre os animais. Usando métodos que minimize a ansiedade também reduzem os fatores de confusão e melhora as respostas durante procedimentos experimentais, levando a resultados científicos mais robustos. 
Atualmente, o emprego de camundongos na experimentação animal, abordando sua biologia geral, fisiologia de reprodução, sistemas de criação, genética, habitação, alimentação, manejo, dor, eutanásia, técnicas de risco desenvolvidas na experimentação, coleta de sangue, experimentos farmacológicos e toxicológicos é bastante utilizado em laboratórios durante ensaios pré-clínicos. Dentre as condiçóes necessárias durante a experimentação animal a gaiola é um ponto fundamental para se obter as condiçôes ideais de conforto e bem-estar dos animais. O material de construçâo varia de acordo com a espécie animal alojada, sendo preferencialmente de material leve, durável e isolante térmico, evitando-se materiais que dificultem a higienização e esterilização. Além disso, a arquitetura deve facilitar o acesso à água e ao alimento, de forma a propiciar conforto, bem-estar e evitar competição entre os animais ${ }^{7}$.

As gaiolas utilizadas na experimentaçáo com animais convencionais de laboratório tendem a manter dimensões padronizadas. Essas dimensões são de fundamental importância, uma vez que pode haver efeitos negativos sobre o comportamento de camundongos induzindo respostas de medo e de ansiedade. Como consequência, os resultados de experimentos com animais poderiam ser alterados.

Além das dimensôes da gaiola, deve ser adotado um protocolo padrão para lidar com camundongos de laboratório. Dentre essas condiçôes necessárias, um método simples de manipulação como pegá-los pelo meio da cauda e não pela de ponta atende as práticas preco- nizadas e reduz resultados negativos que podem ser observados em estudos comportamentais. Diante dessas perspectivas, os resultados do referido trabalho sugerem que a manutenção de dez ou vinte animais por gaiola não produz nenhuma alteração significativa nos níveis de ansiedade dos mesmos, sendo dessa forma, indiferente manter dez ou vinte camundongos por gaiola que segundo os autores precisa ser melhor investigado os parâmetros comportamentais relacionados com a ansiedade sob essa condição.

\section{REFERÊNCIAS}

1.Bellei PM, Gomides SC, Souza JOT, Mourăo-Júnior CA. Influência do número de animais por gaiola sobre o nível de ansiedade em camundongos. Rev Neurocienc 2011;19:591-4.

2.Graeff FG. Neurobiologia das doenças mentais. 5a edição. São Paulo: Lemos Editorial, 1997, 184p.

3.Kaplan IH, Sadock BJ, Grebb JA. Compêndio de Psiquiatria. Porto Alegre: Artmed, 1997, 1584p.

4.Pellow S, File SE. Anxiolytic and anxiogenic drug effects on exploratory activity in an elevated plus-maze: a novel test of anxiety in the rat. Pharmacol Biochem Behav 1986;24:525-9.

http://dx.doi.org/10.1016/0091-3057(86)90552-6

5.Pellow S, Chopin P, File S, Briley M. Validation of open-closed arm entries in an elevated plus-maze as a measure of anxiety in the rat. J Neurosc Meth 1985;14:149-67.

http://dx.doi.org/10.1016/0165-0270(85)90031-7

6.Lister RG. The use of a plus-maze to measure anxiety in the mouse. Psychopharmacology 1987;92:180-5.

http://dx.doi.org/10.1007/BF00177912

7.Chorilli M, Michelin DC, Salgado HRN. Animais de laboratório: o camundongo. Rev Ciênc Farm Básica Apl 2007;28:11-23. 